\section{PRIMEIRA LIÇÃO DE UM BREVE CURSO DE DIREITO ADMINISTRATIVO}

\section{Ruy Cirne Lima}

1. Centro da vida jurídica é a vontade livre. O ato jurídico é uma declaração de vontade $\left({ }^{1}\right)$; o domínio, "expressão da nossa vontade sôbre a natureza física" $\left({ }^{2}\right)$; a obrigação, uma limitação da vontade $\left(^{3}\right)$

No Direito Administrativo, o centro do sistema é, também, naturalmente a vontade livre; mas, diversamente do que sói acontecer no Direito Privado, a vontade aqui é livre, mas não autônoma, - livre, mas sujeita a normas jurídicas cogentes que a dirigem a um fim predeterminado ou, ao menos, predeterminável. De tal sorte, ao demais, a vontade se vincula, em nossa disciplina, ao fim, a ela proposto que "prima facie" poderia pretender-se (mas sem razão) houvesse sido, aquela, por êste totalmente substituída.

No Direito Privado, as relações jurídicas consubstanciam-se, de regra, em direitos subjetivos, dos quais Windscheid disse que consistem em um poder da vontade, conferido pela ordem jurídica $\left(^{4}\right)$. Sem aderir ao conceito, cabe, entretanto, recordá-lo em contraste com a noção de administração, predominante no Direito Administrativo, da qual se enucleia um tipo distinto de relacionamento jurídico, essencialmente finalístico, uma relação jurídica polarizada por um fim, tendo como fonte uma vontade, livre certamente, mas, enquanto adstrita ao fim, certamente não autônoma $\left(^{5}\right)$.

Esse dirigismo da vontade, que tão saliente se revela no Direito Administrativo, corresponde à natureza dêste, como a autonomia da vontade no Direito Privado se lhe ajusta às características incon-
fundíveis.

O Direito Administrativo é, "lato sensu", o ordenamento jurídico intrínseco da Cidade terrena, da comunidade social organizada em que o homem vive nesta terra. O Direito Privado é, à sua vez, o direito

(1) Cód. Civ., art. 86

(3) Dig., lib. L. tit. XVI Direito das Cousas, t. I, Rio de Janeiro, 1906, p. 78

(4) Lehrbuch des Pandeltenrechts, Ed. Kipp t. I Frantef. 108

(5). Nossa preparagño à Dogmática Jurídica, t. I. Flegrankurt am Main, 1906, p. 156

do homem como tal, em face de sua vocação temporal e de seus destinos eternos. No Direito Administrativo, o homem é, por excelência, o destinatário dos benefícios que, das relações jurídicas, resultam ou podem resultar, e secundária ou mediatamente, sujeito delas. No Direito Privado, é o homem, antes de tudo, o sujeito autônomo dessas relações, e secundária ou mediatamente, o seu beneficiário $\left({ }^{6}\right)$.

Não significa, é claro, quanto levamos dito, que o Direito Administrativo não repouse, como o direito em geral, sôbre a vontade. Faltar-lhei-ia conteudo moral, se assim fôsse. Significa, ao invés que, no Direito Administrativo, diversamente do que, de ordinário, acontece no Direito Privado, a vontade se há de determinar impessoalmente, em obediência ao fim, a ela proposto, e não de modo autônomo, segundo a regra que, pessoalmente, a si própria, estabeleça. A impessoalidade na determinação da vontade é o consectário natural da vinculação dela ao fim, que lhe é predeterminado. $\mathrm{Na}$ verdade, a correspondência perfeita entre a vontade e o fim, a que deve ela tender, importa necessàriamente perfeita impessoalidade na determinação daquela, quer dizer, o fim, e não a inclinação pessoal do agente, determina o ato.

Essa impessoalidade marca o lugar do Direito Administrativo nos quadros do direito positivo. A risco de sugerir mais um critério de distinção entre o Direito Público e o Direito Privado, podemos e devemos sinalar a impessoalidade na determinação da vontade como uma nota, ao menos, do conceito de Direito Público.

Materialmente, a impessoalidade na determinação da vontade traduz o devotamento integral do agente ao fim que lhe é predeterminado, ou, seja, em têrmos de Direito Público, ao bem comum; ou, especificamente, em têrmos de Direito Administrativo, à utilidade pública $\left({ }^{\top}\right)$. Formalmente implica, a impessoalidade na determinação da vontade, a abolição das contingências pessoais, a benefício de uma fixação como absoluta das relações jurídicas subsumidas na norma de direito. Não é despiciendo observar-se que as normas cogentes são também denominadas "normas absolutas" $\left({ }^{8}\right)$, a par de que, no Direito Administrativo, sempre chamou a atenção o fato de que se the pede que "determine", "fixe" as relações jurídicas administrativas, ao invés de simplesmente regulá-las $\left({ }^{9}\right)$.

Essa mesma impessoalidade explica-nos, pois, do mesmo passo, a ausência, que a jurisprudência clássica já indicara $\left({ }^{10}\right)$, de normas dispositivas ou supletivas no Direito Administrativo. A liberdade da vontade, que se reflete em tais normas, cede ante o dirigismo da von-

(6) Cf. Savigny, System des heutigen Römischen Rechts, t. I, Berlin, 1840, \& 9 . 1942 , p. 12 a 14. istema do Direito Civil Brasileiro, t. I., Rio de Janeiro, 1938, p. 105 (9) Espínola, Sistema do Direito Cöril Brasieiro, t. T, Rio de Janeiro, 1938, p. 105. (10) Dig., lib. II, tit. XIV, de pactis, fr. 38. 
tade, dominante em nossa disciplina e, em maior ou menor extensão, Goldschmidt adverto Público. No Direito Processual, de resto, James crição do juiz rosure arbítrio, ou dis-

2. Direito, por excelência cogentes, e não dispositivas ( $\left.{ }^{11}\right)$.

toca necessàriamente todos os mais Cidade, o Direito Administrativo ângulo, dir-se-ia caber-lhe os mais ramos do direito. E, olhado dêsse positivo. $\mathrm{Na}$ realidade, centro mesmo de todo o sistema jurídico também a Cidade existe: "omne justema é o homem, para o qual est" (1,2) Cidade existe: "omne jus hominum causa constitutum Mas induvidoso é que, como a Cidade aflora todos os aspectos
da vida exterior do homem, assim também cebe subsídios e achêgas de todombém o Direito Administrativo recebe-os e assimila-os, in de todos os ramos do direito positivo. Redo-os, na mesma medida Transmite-lhe o Direito Privaípios fundamentais.

Administrativo faz da liberdade um a idéia de liberdade; o Direito a figura da discreç̃o adminde um dever irrenunciável e surge, então, a idéia de executoriedade; o enderêço processual de autor a réu Direito Administrativo, tira-lhe dos indivíduos impessoalmente, a réu, dirige-a contra a universalidade executoriedade administrativa, e assim a transforma no que se chama. sanção e, desvinculando-a da noçazo o Direito Penal a idéia de mente considerado liga-a noção de proteção a um bem subjetivade proteção da ordem jurídica, invés, o Direito Administrativo à noção derada, e cria, de tal modo, a ficurativamente, impessoalmente consicontribuição capital à sua formac̃a do ilícito administrativo (13). A ministrativo, do Direito Constituão, recebe-a, porém, o Direito $\mathrm{Ad}$ Direito Público, o seu tronstitucional. Este é como o eixo de todo o no Direito Constitucional tronco mesmo (14). Ainda aqui, entretanto, se no Direito um bem, por isso que suscé já a utilidade pública. O bem comum é objeto de um gôzo sensível l em ser fruído como tal, - um "frui", referido ao homem, ao indivíduo em tais condições, sòmente pode ser mesma, desprovida, ela própria em sociedade, e nunca à sociedade ao revés, supõe meramente a de sensibilidade. 'A utilidade pública, consecução mesma a pode realizar, devendo, ao di"; e essa utilização, a sociedade lizá-la entra no elenco das funcões essenis, acrescentar-se que o reacial $\left({ }^{15}\right)$.

(11) Teoria General del Proceso, Barcelona, 1936, p. 72

(13) Nossa Introdução cit., p. 30 a 32 . fr. 2.

(14) Santi Romano, Prie Ubbertretung, t. I, Leipzig, Direito Penal, particularmente,

(14) Santi Romano, Principii di Diritto Amministratico Italiano, Milano, 1912, p. q
(15) Nossa Introdunão cit., p. 12 e. 13 .
A utilização dos meios adequados à consecução do bem comum delineia-se e fixa-se através do ordenamento jurídico intrínseco da comunidade social; a utilidade pública constitui, assim, o fim último e a matéria-primeira do Direito Administrativo, que "lato sensu" não é senão, precisamente, o ordenamento jurídico intrínseco da Cidade. Recebendo, pois, a contribuição decisiva do Direito Constitucional, ainda essa, o Direito Administrativo a transmuda, ao assimilá-la, como, de resto, segundo vimos, acontece a tôdas as demais contribuições, de que se enriquece.

Ante a originalidade específica do Direito Administrativo e, do mesmo passo, a variedade dos materiais de que se forma, não admira, portanto, seja, êle, aqui apontado como direito especial relativamente ao Direito Político, apresentado em uma concepção mais ampla do que em sua forma clássica, como a participar simultâneamente do Direito Público e do Direito Privado ${ }^{16}$ ); e ali o definam como direito especial, relativamente ao Direito Civil, êste, porém, entendido em sentido largo e genérico, à maneira romana, de sorte a abranger, ao mesmo tempo, matérias de Direito Público e matérias de Direito Privado $\left({ }^{17}\right)$. Transparece, realmente, nessa inacomodação aparente do Direito Administrativo aos quadros clássicos do direito positivo, o vigor de seu conteudo original, em contraste com a proveniência diversa dos materiais nêle coadunados, saídos de todos os ramos do direito.

Por certo, como direito especial, ao Direito Administrativo não se exige que se enxerte êle como dependente exclusivo, em um ramo jurídico preexistent, o qual se chamaria, então, relativamente àquele, direito geral. Qualificar-se um ramo do direito como direito especial indica meramente que tem êle uma formação derivada, simples ou compósita. E' sempre possível rastrear-lhe a origem anterior, unitária ou múltipla, dos materiais integrativos: "semper specialia generalibus insunt" ( $\left.{ }^{18}\right)$. Se se quisesse, não obstante, designar-lhe, ao Direito Administrativo, como a todo direito especial, um direito comum ou geral por têrmo de contraste, bastaria referi-los ao que Georges Renard excelentemente denominou "direito comum nacional", êsse, quase indefinível, núcleo de individualização das instituições jurídicas de um povo $\left({ }^{19}\right)$.

3. Baste-nos, entretanto, reconheçamos que tem a nossa disciplina uma formação derivada; é, fora de dúvida, direito especial. Mas pela sua essência mesma, como deixamos entrevisto, o Direito Administrativo, sem embargo da contribuição privatística que nêle influi, da sua posição avulsa nos quadros do direito positivo, há de ser classificado como Direito Público.

(16) A. Posada, Tratado de Derecho Administrativo, Madrid, 1897, t. I, p. 77.
(17) L. Meucci, Istituzioni di Diritto Amministrativo, Torino, 1909, p. 7.

(18) Dig. lib. L, tit. XVII, de regulis juris antiqui, fr. 147. 
A impessoalidade na determinação da vontade é o critério que se nos oferece para essa classificação. Certamente, há no Direito Privado, tal ou qual impessoalidade na determinação da vontade, em tuAssim, no respeita à noção de administração, ali também encontradiça. curadores, dirigentes de a determinação da vontade dos pais, tutores, to aos bens que ade corporaçoes, sociedades e fundações, enquanmeramente se reconhece a . Essa impessoalidade, porém, pela qual Direito Público, quanece a comunhão, entre o Direito Privado e o qualificada com, quanto ao conceito de administração, se pode ser respeita, mostra-se "ad extra", antes, como círculos de interêsses a que çâo, mais ou menos definida", antes, como um reflexo da personificarante a sociedade havida, désses mesmos círculos de interêsses pecomo partes em que se inserem êles

No Direito Público, ao revés, depara-se-nos a impessoalidade na determinação da vontade levada ao máximo. Aqui, o círculo de na terêsses, a que a administracão respeitáximo. Aqui, o circulo de inmesma, e a limitação ntação respeita, é coextensivo com a sociedade

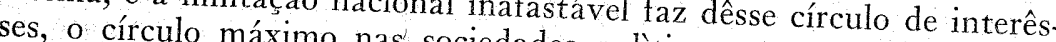
Bártolo sinalava quimo nas sociedades politicamente organizadas. Já comunidade "superiorem nos recognesposta de decisão do regente de "ipse populus. . qui ipsum recognoscens", haveria de ter como juiz

Dirito Público, de reficialem fecit" (20).

Direito Público, de resto, o Direito Administrativo nem por isso
a sua independêncio não é alo de pendencia. E, de outro lado, o mesmo Direito Público disse admiràvelmente: bonum diverso do Direito Privado. Baldo nec privatum sine publico" $(21)$ publicum non (est) sine privato,

\section{FUNCION PRIVADA Y FUNCION PUBLICA}

\section{DEL PROCESO}

\section{Eduardo J. Couture (*)}

\section{1. - Elementos del proceso}

El proceso civil es, en su forma, un conjunto de actos jurídicos. Como su nombre lo indica, estos actos se hallan ordenados en forma sucesiva. Colocados unos tras otros con arreglo a un órden ya determinado, adquieren en sua continuidad un sentido de desarrollo y desenvolvimiento. De la misma manera que los procesos físicos, químicos o biológicos, el proceso civil es un fenómeno continuativo, dinámico.

Los actos del proceso civil se registran normalmente en documentos o piezas escritas, en los cuales se consigna la voluntad jurídica de las partes y de los órganos del poder público. Esos documentos reproducen los actos jurídicos, dándoles forma permanente.

Aunque tales piezas escritas no constituyen, propiamente, los actos jurídicos, sino su representación, se acostumbra a llamar indistintamente proceso a los actos y al expediente (dossier) en el cual esos actos se hallan recogidos o registrados.

La idea de proceso es teleológica. Su fin y no su forma es el que la define y delimita $\left({ }^{1}\right)$.

El fin del proceso civil es dirimir un conflicto de intereses. De la misma manera que el debate legislativo apunta hacia la sanción de la ley y de la misma manera que el debate administrativo apunta hacia el acto administrativo, el proceso civil apunta hacia la cosa juzgada que dirime por acto de la autoridad un conflicto de intereses.

(*) Catedrático de Derecho Procesal Civil de la Facultad de Derecho de Montevideo. WA.OH, Der Rechtschutzsanspruch, en "Zeitschriftfür deutschen Zivilprozess" t. 32, p, 5 ; y SCHONKE, La necesidad de la tutela juridica, en "Revista Ju
díca de Córdoba" to 2 p. 57 y en "Rivista di Diritto Processuale", 1948, p. 132 . 